REVISTA ANDALUZA DE ANTROPOLOGÍA.

NÚMERO 11: TRABAJO Y CULTURAS DEL TRABAJO EN LA GLOBALIDAD HEGEMÓNICA

SEPTIEMBRE DE 2016

ISSN 174-6796

[pp. 146-173]

http://dx.doi.org/10.12795/RAA.2016.11.07

Recibido: 18/04/2016

Aceptado: 12/07/2016

\title{
“MOVER PEDRA”: GLOBALIZACIÓN, TRANSFORMACIÓN DE LA INDUSTRIA CANTERA Y DISPERSIÓN VINCULATIVA EN GALICIA
}

\section{"MOVE STONE": GLOBALIZATION, TRANSFORMATION IN INDUSTRY OF QUARRY, AND DISPERSAL OF SOCIAL LINKS IN GALICIA}

\author{
Enrique Couceiro Domínguez \\ Universidad de La Coruña
}

\section{Resumen.}

La centralidad de una determinada actividad productiva configura el conjunto de la vida social, determinando las expectativas y posibilidades de empleo de la población, y sus pautas de sociabilidad. El desarrollo de la cantería industrial en una comarca del sur de Galicia ha convertido a esta actividad en referente central dentro de un panorama socioeconómico en rápida urbanización. La transformación de la cantería tradicional en industrial se ha fundamentado en dos ejes estratégicos articulados. Por un lado, el desarrollo de una estructura de interdependencia asimétrica entre empresas altamente capitalizadas, competidoras en un mercado global, y pequeñas cuadrillas que producen a destajo para aquellas, manteniendo una cultura organizativa y un ethos reciprocitario tradicionales. Por otro lado, una pauta tradicional de formación de los aprendices basada en el adiestramiento en el propio proceso laboral, que torna a los canteros, y por extensión a la juventud local, en reacios a las políticas oficiales de formación reglada. Paralelamente, la desaparición de la cantería manual, y de la agricultura, han provocado 
que el 'modo laboral de relación' que antaño posibilitaban haya dejado de ser marco de referencia para la convivencia vecinal de aldea; papel que hoy adoptan los centros culturales parroquiales.

\title{
Palabras Clave.
}

Cultura del trabajo, ritual, cantería, destajo, formación laboral, Galicia.

\begin{abstract}
.
The centrality of a particular productive activity shapes the whole of social life by determining the expectations and possibilities of people's employment and its patterns of sociability. The development of industrial quarrying in a region of Southern Galicia has made of this sector a central benchmark within a socio-economic scenery in fast urbanization. The transformation of the traditional quarrying in industrial has based on two articulated strategic axes. On the one hand, the development of a structure of asymmetrical interdependence between highly capitalized companies, competing in a global market, and small crews that produce for them in a paid-per-job system, while maintaining an organizational culture and a traditional reciprocity ethos. On the other hand, a traditional formative pattern of apprentices, based on the training in the labor process in itself. Pattern which makes the quarrymen -and by extension the local youthreluctant to the official education policies. At the same time, the disappearance of manual quarrying and agriculture, have led to that 'work-based mode of relationship' no longer being a frame of reference for the local daily living of village inhabitants. Rather, this is the role adopted today by the parish cultural centers.
\end{abstract}

\section{Keyword:}

Work culture, ritual, quarrying, piece-work, job-training, Galicia

La realización de las actividades laborales presenta una dimensión simbólico-ritual, interpolada con la orientación técnico-material, cuya importancia se hace patente cuando observamos el trabajo como una actividad social tecnológicamente mediatizada que, aunque dirigida a provocar intencionalmente transformaciones útiles de la materia para las demandas humanas, asimismo produce y reproduce -en sus específicos condicionamientos materiales y contextos históricos- modos organizados de relación productiva. La dinámica simbólico-ritual con que el ejercicio laboral forma la experiencia de quienes lo desempeñan, contribuye organizando y normalizando las características concretas del propio proceso del trabajo (incluidas las relaciones técnicas de producción). Este aspecto simbólico-ritual informa y refuerza demostrativamente la conciencia de jerarquías y oposiciones categoriales, la división cualitativa y cuantitativa de tareas, las 
diversidades y asimetrías en la disposición de tiempos y espacios, las desiguales potestades decisorias, la cohesión del grupo respecto al exogrupo, o las normas de cooperación entre compañeros. En este sentido, las performances simbólico-rituales puestas en acto en el ejercicio de la actividad cotidiana constituyen componentes necesarios para llevar a cabo la misma función tecnológico-material del proceso productivo, pues de ellas dependen la generación de las sinergias y la organización de recursos humanos.

\section{LA ACCIÓN PERFORMATIVA DEL TRABAJO SOBRE LOS PROCESOS ORGANIZATIVOS, VINCULATIVOS E IDENTITARIOS.}

En la visión antropológica clásica de la acción humana se discernía expresamente entre los aspectos expresivos y los instrumentales, identificando el ritual con el desarrollo de los primeros y la "rutina tecnológica" -en términos turnerianos- con el despliegue de los últimos. Frente a esta diferenciación -cuestionable, a mi entender, desde el punto en que, como argumento más adelante, el hecho mismo de la ejecución de las actividades tecno-instrumentales constituye inherentemente el despliegue de un acto comunicativo, ante todo en escenarios de trabajo colectivo-, Leach (1976) reconoce la imposibilidad de establecer una distinción útil entre ritual y costumbre. En consonancia con el sentido con que este autor aborda al ritual como "elemento de comunicación del comportamiento humano", cuyo cometido consiste en reafirmar las diferencias dentro de una red sumamente compleja de relaciones sociales (Leach, 1976:386), entiendo que "lo ritual" no se agota en el 'rito' o las 'ceremonias': resulta un componente esencial también de la actividad laboral, hasta el punto de poder establecerse una parcial ecuación conceptual entre ritualidad y tecnología (Couceiro, 2008). Para dar una definición de lo ritual específicamente referida al contexto del trabajo, ésta representaría la faceta de toda acción laboral que, en base al despliegue de la formalidad, reiteración, carácter ejecutivo, y otros rasgos (Rappaport, 2001) entreverados en su propio ejercicio competente, convierte esa acción en una intervención configuradora y reguladora de las concretas relaciones e identidades sociales del grupo de intervinientes en el proceso. Es decir; la acción ritualizada, en el trabajo como en otros órdenes de la vida, puede homologarse a una técnica específica de producción, reproducción y gestión de lo social $y$ sus representaciones. El recurso práctico a estas ritualizaciones opera comunicando mensajes canónicos inscritos en mensajes autorreferenciales, que objetivan, demuestran e inculcan imaginarios y valores culturales que informan cualitativamente la interacción en el ámbito de trabajo. Junto con ello, establece asimismo los ciclos temporales de la experiencia (jornada, mes, campaña...). Al respecto, señalo el interés de Asad (1983) por resaltar la instrumentalidad de lo ritual: lo que hace más que lo que dice; y, en lo que hace, la implantación de un discurso de poder. Bloch (1989), a su vez, define los rituales como afirmaciones que no admiten argumentos, no sugieren alternativas, y no pueden ser contestadas. 
Insertando físicamente a los actores en el (dis-)curso de la acción formalizada, reiterativa, es como la ritualidad laboral despliega su poder; o, siguiendo a Kelly \& Kaplan (1990:140), "The special power in ritual acts, including their unique ability to encompass contestation, lies in the lack of independence asserted by a ritual participant, even while he or she makes assertions about authority". Esto explica que la realidad socio-organizativa y el esquema de valores actualizados ritualmente sean demostrados -y organicen las experiencias vividas- tanto por propietarios como por trabajadores, jefes como empleados... en tanto que participan de esa acción laboral normalizada.

Con todo, lógicamente es preciso añadir que tal ritualidad laboral nunca opera en el vacío: sólo es efectiva correspondiendo a factores y presiones ejercidas desde contextos sociales, económicos, político-normativos y culturales de mayor escala que la mera cantera, edificación o factoría de automoción. Una correspondencia a menudo instrumental y subordinada. La mecanización de la producción; el mercado nacional o internacional y sus oscilaciones y crisis; la intensidad y nivel en la competencia empresarial; las estrategias de formación-control continuados de los trabajadores; el grado de diversificación de las fuentes de empleo y especialización; o la eventual apelación estratégica a clichés de etnicidad, género o procedencia con vistas a consolidar o transformar actitudes hacia el reparto de las posibilidades laborales, representan algunos de estos factores. Factores que operan a diferentes escalas, condicionando la organización, identificaciones y convivencia laboral del escenario concreto del taller o de la cantera. Así por ejemplo, Trist y otros (1963) afirman que en la minería, la mecanización conlleva la fragmentación y ruptura del grupo de trabajo que se autorregula y selecciona autónomamente sus integrantes. Esto conduce al incremento de las tasas de estrés, absentismo y reducción de la productividad. Esta tendencia desfavorable desaparece en sistemas que estimulan la adaptación mutua de hombres y máquinas reteniendo el modelo tradicional, autónomo y localizado, del grupo de trabajo.

Volviendo al proceso laboral concreto, ordenado según esquemas o "procedimientos prácticos" (Couceiro, 2008) tradicionales o industriales de regulación y secuenciación de la actividad, es conveniente añadir que su efecto de moldeado simbólico-ritual no se agota en la estructura y organización del grupo de operarios, sino que, según la centralidad del tipo de actividad productiva, puede proyectar su influjo configurativo al conjunto de la vida social. Resulta evidente cómo sectores específicos de actividad, con distintivas culturas del trabajo, alcanzan a ejercer una influencia nuclear e histórica en la vida de numerosas localidades, organizando y condicionando -o determinando- las expectativas y posibilidades de empleo, el rango de alternativas de adaptación económica, la dinámica temporal de la actividad de la población, sus modos de estratificación y los habitus que distinguen localmente las clases sociales. En referencia a esas actividades, la población desarrolla su imaginario y concepciones sobre los modos de comportamiento, rasgos, valores y símbolos mediante los que se forjan los patrones locales de masculinidad- 
feminidad, las señas de la identidad etaria y las perspectivas vitales, además de afectar a aspectos concatenados, como los modos, tiempos, y emplazamientos de relación social, esparcimiento, estilo y dotación de ceremonias y celebraciones festivas.

Por supuesto que aunque esta (meta-) influencia del simbolismo y ritualidad laborales a escala local resulte más indirecta, puede ser tal que llegue a proyectarse más allá de la coyuntura histórica en que una actividad sea el único motor dominante de la economía. Es el caso de la cantería -y la elaboración y construcción en piedra, como actividades históricamente asociadas- en diversas localidades situadas a caballo de las comarcas de $\mathrm{O}$ Condado, el Baixo Miño y el Louro, en el sur de Pontevedra. El devenir de esta cantería constituye el argumento etnográfico de este trabajo.

La citada, conforma un área rurubana hoy en día altamente industrializada, productivamente diversificada (polígonos industriales de Cerquido, A Granxa, PorriñoAtios; Mos; polígono de Salvatierra), y en la que desde la última década del s. XX la cantería extractiva ha visto parcialmente limitada, aunque no desplazada, su centralidad económica y sociocultural por la pujante diversificación industrial (automoción, industrias químico-farmacéuticas, cerámicas, componentes industriales, maquinaria agraria e industrial) y de empresas de servicios. La cantería ha llegado a plasmar su importancia simbólica en la caracterización local de municipios y parroquias (así, Atios en Porriño, o San Jorge y Parderrubias en Salceda de Caselas) como "terra de canteiros" o "parroquia de canteiros"; expresiones que establecen la ecuación retórico-moral entre población, territorio y actividad, y sugieren específicamente la concentración en esas localidades de destacadas explotaciones canteras, connotando riqueza, empleo, capacidad de consumo y de gasto en edificaciones, infraestructuras comunitarias y celebraciones festivas.

\section{LA CANTERÍA TRADICIONAL EN LA ÓRBITA DEL MODO DE VIDA ALDEANO}

Aunque ya en la década de los cuarenta, junto a algunas empresas químicas, se desarrolla progresivamente la cantería a escala industrial en Atios (parroquia porriñesa donde se emplaza la mayor explotación mundial de cantería del granito) y en Salceda, la antigua cantería de ejecución manual y paleotécnica continuó menudeando y basándose, hasta su desaparición a mediados de los ochenta, en la explotación de penedos y de bolas (roquedales sueltos) de los montes próximos, desarrollada por pequeñas cuadrillas autónomas. Para esta producción se empleaba instrumental manual (picos, barrenos, martillóns, pinchotes, dinamita, bujardas, sinfins, carros), y dependía de una demanda comarcal, asociada a la cultura y economía campesinas de aldeas y villas de los contornos. Ante la exigüidad del negocio local -ligado a la construcción en piedra de viviendas y dependencias aldeanas por los propios canteros- la alternativa consistía en los desplazamientos de temporada de las cuadrillas (a Madrid, Orense, León, País Vasco, etc.), para aprovechar oportunidades 
tanto de explotación como de construcción. Pero en el ámbito inmediato, las pastas para cierres de fincas, postes para emparrados, bloques para socalcos y perpiaños y lousas para edificaciones aldeanas, resumían esa modesta demanda local. Tal limitación se debía al sometimiento a otra cultura del trabajo entonces dominante. El concepto de "cultura del trabajo" alude al:

"Conjunto de conocimientos teórico-prácticos, comportamientos, percepciones, actitudes y valores que los individuos adquieren y construyen a partir de su inserción en los procesos de trabajo y/o de la interiorización de la ideología sobre el trabajo, todo lo cual modula su interacción social más allá de su práctica laboral concreta y orienta su específica cosmovisión como miembros de un colectivo determinado" (Palenzuela, 1995).

Y es que, hasta avanzada la mitad del siglo XX, la cultura del trabajo dominante, aquella que generaba tal demanda, situando a la cantería como satélite de sus propios requerimientos, y troquelando identidades, representaciones, expectativas, valores y modos de vida, era una cultura del trabajo labriega, erigida en la conjunción entre sistemas de axudas vecinales en las faenas del policultivo doméstico, y patronazgo ejercido por casas fortes que daban trabajo al jornal. Tal cultura del trabajo labriego hacía gravitar poderosamente la interacción vecinal dentro un ámbito aldeano-parroquial de relación cotidiana. Y en correspondencia con su status secundario en este viejo panorama aldeano, el oficio del canteiro recibía un cliché negativo, denigrado como un "traballo bruto", dañoso y parco en beneficios; quienes a él se dedicaban "só valían para iso, pa pegar có pico, porque non tiñan outro xeito de gañala vida”.

En ese contexto, el grupo de canteros se organizaba bajo la dirección de un jefe o canteiro, propietario de la ferramenta o instrumental, y beneficiario de una explotación en terrenos particulares o de alguna comunidad vecinal de montes, bien adquiriendo el penedo, bien satisfaciendo un canon acordado sobre la producción. El jefe trabajaba mano a mano sobre la bancada junto a una cuadrilla de 4-7 pedreiros, integrada por oficiales veteranos, encargados de poñer os tiros, desprender los grandes bloques de piedra, y extraer los postes y pastas con pico, martillón, pinchotes y ferros, auxiliados por peóns; y por pinches o aprendices que desarrollaban tareas auxiliares en el desescombro, alcanzaban la ferramenta o picaban y abujardaban perpiaños. La ocupación de estos rapaces -generalmente hijos o sobrinos de canteiros o pedreiros locales, pues al oficio se accedía por transmisión parental combinada con contactos amicales- resultaba inestable, condicionada por las ayudas que debían prestar en la labranza doméstica. Con su primera paga, era obligado que el aprendiz convidase a una rolda de viños a sus compañeros de cuadrilla: espaldarazo a un novel, que renovaba ritualmente la cohesión del grupo.

El trabajo en la cantera dependía estrictamente de la luz solar, abarcando toda la jornada, y exigiendo una coordinación colectiva de esfuerzos en labores tales como turnarse 
introduciendo pinchotes progresiva y rítmicamente en bloques de granito, a golpe de martillón, para rachar pastas. La práctica se basaba en la plena competencia del grupo en el control y ejecución técnica del proceso productivo, salvo por la prestación ocasional de ayudas entre grupos de canteiros próximos desde una norma de reciprocidad ("os uns polos outros") cuando la magnitud de cierta maniobra, como virar un pastón pesado, desbordara la capacidad de la cuadrilla. En la memoria de antiguos canteiros, el trabajo salía adelante por el "compañerismo" y una coordinación 'mecánica' en tareas colectivas, desarrolladas a fuerza de brazos. El mismo planteamiento de la labor refrendaba esta normal coordinación unificante del grupo de colaboradores, por más que también se articulase sobre el reparto de tareas específicas en función de la experiencia y la veteranía. Un momento tecno-ritual particularmente 'nivelador' de condiciones categoriales era ese de virar un pastón -desplazar una gran pieza de granito-, tarea que demandaba el concurso general mediante ferros de monte, cuñas y rolos de madera. La sinergia de esfuerzos exigía sincronizar rítmica y poéticamente la suma de empujes: "iOoooump!! iiOoooump!! ¡iOoooump!!! /Ahí vai /Ahí ven / Entra ti /E eu tamén".

Razón tecno-ergológica y demostración organizativo-ritual -a cuya vinculación inherente me he referido al principio del trabajo como la doble orientación, instrumental y comunicativa, de la actividad laboral- se concertaban en el despliegue rutinario del trabajo, aunque habitualmente en contrapunto a ese momento de unificación descrito: la realidad de las jerarquías y de la desigual experiencia personal eran fáctica y reiteradamente demostradas en las asimetrías en la potestad de decidir -cosa del jefe- la intensidad de esfuerzo en función de los objetivos de producción diarios; en las tareas expertas, propias de oficiales, como trazar solventemente la línea de corte de una banca de roca tras buscar su norte y andar ( la veta de corte: quehacer crítico que requiere ojo experto), o manipular los explosivos para poñer un tiro donde se barrenó... en contraste con el afanarse despejando de tierra y xabre la base del penedo a explotar, o preparar la ferramenta utilizada: menesteres de peóns y aprendices que los pedreiros de mayor oficio tendían a eludir. Acorde a tal reparto de funciones era la distribución de espacios, que distinguía jerarquías categoriales según la dualidad arriba da bancada / abaixo da bancada, que connotaba [riesgo/seguridad] :: [labor crítica / labor auxiliar] :: [centralidad/marginalidad] :: [experiencia/inexperiencia] :: [autoridad/subordinación]. Las disponibilidades de tiempo, en cambio, no categorizaban marcadamente como en el caso de la cantería industrial, pues la totalidad de la cuadrilla trabajaba toda la jornada, compartiendo las mismas paradas para almorzar. Sólo contribuía a marcar una diferencia: los aprendices tenían prescrito permanecer algo más para recoger el instrumental al cabo del día. Las diferencias en la retribución, a paga, en contraste, expresaban acentuadamente las distancias entre categorías. 
Al término de la jornada, entre las 7-8 de la tarde, los pedreiros, como cualquier labriego, concurrían en un mismo marco acostumbrado de sociabilidad aldeana, las tabernas locales, para matalo tempo y tomar unhas cuncas de viño, departiendo y jugando una mano de truco con otros vecinos. Este 'esquema práctico', organizador de la actividad cotidiana, que hace culminar en ocio vecinal compartido una jornada laboral extensa, apenas trascendía el ámbito aldeano, contribuyendo a reforzar la experiencia de la comunicación y unidad parroquiales mediante la práctica convivencial. Se trataba de un 'esquema práctico' de planteamiento labriego. También podemos rastrearlo en aspectos como la citada cooperación entre cuadrillas contiguas ante la necesidad de refuerzo de mano de obra, informada por el ethos reciprocitario, reflejo cantero del que regía las generalizadas axudas recíprocas de los labradores estremeiros en sus leiras, bajo la premisa del "hoxe por ti, mañán por min".

En conjunto, la actividad canteril tradicional no se orientaba mediante una norma de producción intensiva de granito, sino que se dirigía al auto-suministro de la piedra que el propio canteiro precisara para los encargos de obra que apalabraba en el entorno comarcal, encadenando en un continuo empresarial la actividad extractiva con la construcción.

\section{EL AUGE DE LA CANTERÍA INDUSTRIAL Y DE LA CONSTRUCCIÓN ENTRE LOS AÑOS '80 Y 2007. NUEVAS FORMAS DE ACUMULACIÓN; TRANSFORMACIONES EN LA ORGANIZACIÓN DEL TRABAJO}

La actividad de la cantería en Porriño y Salceda experimentó transformaciones progresivas, radicales e irreversibles desde la década de los '70 del s. XX. El repunte lo anticipa el establecimiento, durante los ' 60 , del Polo de Desarrollo Vigo-Porriño, y lo impulsa resueltamente la expansión y consolidación de un mercado del granito para la construcción cuya magnitud crece exponencialmente hasta el presente, superando el ámbito comarcal y la lógica campesina o villega. El desarrollo de la cantería industrial es estimulado inicialmente por la demanda de grandes bloques ("azucarillos") por empresas italianas, aunque también se asocia al crecimiento urbano en España. Más adelante, la demanda se internacionaliza: el granito "rosa Porriño" reviste hoy fachadas neoyorquinas, y es solicitado desde Italia hasta China. Desde este incremento de la demanda a gran escala de bloques, la organización, orientación y capitalización productivas se transforman sistemáticamente. Así, desde la década de los '90 se difunden empresas no sólo -o no ya- dedicadas a la cantería extractiva, sino a la elaboración de transformados graníticos (aserrado y pulimentado de tableros, perpiaños, losetas, placas y sillares), que consumen miles de $\mathrm{m}^{3}$ dirigidos al mercado internacional a través del puerto de Vigo, con lo que el valor industrial añadido pasa a retenerse en la comarca. Pronto, la implantación de estos talleres de procesado de la piedra (Altamira, RECSA, Granisa, Graninter, Granitos de Atios, Granitos del Louro...) llegó a aportar el mayor valor de la producción y el grueso de oportunidades de empleo en el sector. Con esta tendencia, durante el cambio de 
milenio el mercado de elaborados alcanzó cifras de 9000 millones de ptas., por poco más de 5200 millones el de bloques en bruto. Sin embargo, la dependencia directa del sector granitero -unas 109 empresas- respecto a la demanda de la construcción, provocó altibajos productivos durante la segunda mitad de los años noventa, afectado por la competencia italiana. Esta fluctuación dio paso a un nuevo auge a principios del nuevo milenio, impulsado por la mecanización integral, diversificación y aumento de las dimensiones de negocio de la mayoría de las empresas. Por aquel entonces, el sector constructivo gozaba de una época de prosperidad, debida a un desarrollo inusitado de la demanda de edificaciones a escala nacional, y particularmente intenso en Salceda. Esta localidad venía destacando, desde los ochenta y hasta 2013-14, como el municipio gallego con mayor y más mantenido crecimiento relativo de la población, debido a su tasa positiva de inmigración juvenil, al convertirse en una ciudad-dormitorio tributaria de Vigo (su censo pasa de 5882 habitantes en 1986 a 6018 en 1999, para dispararse a 8890 en 2014). Por otra parte, el auge socioeconómico no vino estimulado exclusivamente por el despegue cantero y constructivo, pues en él tuvo gran influencia la creciente y diversificada demanda de empleo industrial -en parte inducido- radicado en polígonos próximos: la fabricación de maquinaria, de componentes de automoción, la ocupación en factorías cerámicas, del plástico, o en el procesado de pescado congelado. Con más intensidad aún, entre las décadas de los '90 y los 2010 la actividad en servicios también se diversifica y prospera firmemente hasta ocupar a más de la mitad de la población. Algunas cifras sobre porcentajes de la población ocupada según ramas de actividad en Salceda de Caselas, ilustran a grandes rasgos esa evolución del empleo:

Graf. 1'. Población ocupada según rama de actividad - Salceda de Caselas 1981-2011

\begin{tabular}{|l|l|l|l|l|}
\hline & Agricultura- ganadería & Industria & Construcción & Servicios \\
\hline 1981 & $37.3 \%$ & $25 \%$ & $17.7 \%$ & $19.9 \%$ \\
\hline 1991 & $8.6 \%$ & $36.8 \%$ & $22 \%$ & $32.2 \%$ \\
\hline 2001 & $3.9 \%$ & $40.6 \%$ & $16 \%$ & $39.5 \%$ \\
\hline 2011 & $2.1 \%$ & $31.7 \%$ & $11.2 \%$ & $55 \%$ \\
\hline
\end{tabular}

INE. Censos de población e viviendas. Elaboración propia a partir de datos del INE

En este contexto, en los albores del Siglo XXI el trabajo cantero, de albañilería y en ocupaciones asociadas a la construcción (peones, encofradores, transportistas), bien como autónomos o bien como empleados, resultaba notablemente atractivo, aunque con posterioridad decayese en términos relativos y absolutos. El incentivo fue la abundancia 
de ocupaciones bien remuneradas y no exigentes de formación previa, tras la estela de la gran demanda de obra asociada al despegue urbano de la capital de Salceda y villas próximas. Esa demanda provocó que antes del cambio de siglo proliferasen albañiles expertos y destajistas de cantería que se aventuraron como promotores-contratistas de la construcción, asumiendo el control de todos los aspectos del negocio, y partiendo de la auto-provisión de piedra: una fórmula que se vino estrepitosamente abajo con la crisis de 2007-2014. Así, según un responsable de empleo municipal:

“... también nos enfrentamos a un fenómeno que yo creo que pasó en toda España... que era que cualquier señor que sabía que era un oficial de albañil acababa siendo autónomo, por la propia trayectoria que había aquí de los autónomos, y lo del [ser] autónomo no asusta... en todos los sitios asusta, pero aquí como que era algo normal; $y$ después... mucha de esta gente que era destajista acababa cogiendo dos o tres obreros... acababa montando una empresa de construcción... Y acababa siendo promotor, constructor y tal."

Llamo la atención sobre la "normalidad" localmente asumida de ese perfil de empresariotrabajador autónomo y polivalente que aun suponiendo una forma de adaptación a las oportunidades del mercado actual, está no obstante informado de raíz por aquél modus operandi cantero tradicional que encadenaba extracción y labra de la piedra con la edificación: "Los dos... quien se dedicaba a lo uno [construcción y cantería], pues tenía las dos licencias, efectivamente... Agora o choio ese non hai, pero a construcción sigue sendo en granito."

Ya en la década de los ochenta desapareció la cantería de tradición y tecnología manual, pues los sustanciales incrementos de volumen y ritmo productivo necesarios para mantenerse y lograr posición en el mercado exigieron la mecanización sistemática de las actividades, su especialización en extractivas y transformadoras, el acceso a granito de diferentes variedades y en explotaciones de suficiente capacidad extractiva, y la continua innovación tecnológica aupada en una fuerte capitalización. De este modo, la cantería extractiva fue incorporando instrumental como compresoras, martillos neumáticos, maquinaria perforadora, de corte con hilo diamantado -que sustituye a la dinamita-, retrocavadoras, grúas, y camiones. Los talleres o aserraderos de piedra, a su vez, adoptaron cortadoras, lijadoras, pulidoras, amoladoras, y abujardadoras. Ya entre las décadas de los setenta y ochenta, compelidos a trabajar a destajo, los canteros autónomos, al principio tímidamente y después en cascada, habían adquirido a crédito compresoras y taladros neumáticos, pues pronto fueron conscientes de que:

"O negocio estaba alí, porque hai que pegarlle; é una empresa, e nunha empresa hai que manexar diñeiro, e ten que rendir; e si tiñas una canteira, pois tiñas que mover pedra para gañar; e si eres destajista, tes que sacar o acordado. Traballas a tanto acordado." 
La especialización en dos sectores de actividad se evidencia en la siguiente distribución: de 28 empresas de cantería registradas hoy en Salceda de Caselas, 10 se dedican a la extracción, 11 a la elaboración de piezas de granito, mármol y piedra ornamental (tres de ellas combinándola con montaje), 1 empresa se limita a la comercialización, y únicamente 6 siguen concertando la cantería de extracción con la elaboración de la piedra y la instalación en obra.

A su vez, condicionada por las diferencias de capital y de disposición de tecnología, fue incrementándose la competencia entre canteros por conseguir buenas "cuadrículas" o concesiones de explotación, primando las que garantizaran un gran volumen extractivo y que permitiesen diversificar las variedades de piedra demandadas por el mercado ( "gris mondariz", "rosa porriño", "rosa dante", o "gran perla"). Resultaba estratégico diversificar la producción extraída para responder a esa demanda cada vez más heterogénea de tipos, canalizada a través de empresas elaboradoras, que asimismo importan variedades foráneas de Brasil, Sudáfrica u otras procedencias. Por tanto, esta competencia por las vetas, unida al aumento de la escala de referencia competitiva -ahora global- para desarrollar la empresa, fue produciendo una escisión, según magnitudes de negocio y capital, entre grandes empresas de cantería que monopolizaron derechos de explotación de las principales canteras, y pequeñas cuadrillas de autónomos, forzadas a explotar al destajo concesiones a menudo marginales -peñascos de aprovechamiento técnico más difícil y menos rentable -.

La diversificación de enclaves de explotación y el aumento del volumen extractivo asumido por las grandes empresas forzó entonces un cambio en la estrategia dominante de organización del trabajo en la cantera, que se consolidó y tornó en estructural: una estrategia basada en la combinación de explotación por empleados de plantilla, y de producción a destajo encomendada a esas pequeñas empresas subcontratadas que seguían regulándose en lo fundamental como las cuadrillas de antaño. Así, según un cantero destajista a mediados de los ' 90 :

“(...) eso de poner en marcha una cantera no está al alcance de cualquiera. Es muy difícil poner en marcha una empresa propia... Y por eso, por lo general, la gente entra como empleados en la cantera, para trabajar a cuenta del cantero, o tienes que andar con destajos. También en eso es difícil; hay que pegarle y hay que estar encima al mismo tiempo [esperando la oportunidad, como autónomo], para ver si coges una buena cantera. Pero esas ya están todas cogidas por aquí, por los grandes".

A finales del siglo XX, en la cúspide del nuevo esquema organizativo (Couceiro, 2008:361384), el canteiro por antonomasia, empresario y propietario de una gran explotación, trataba de consolidar su cuota de mercado y aumentar su margen de negocio, compitiendo en escala y calidades a nivel internacional. Aparte de cuidar de la continua renovación tecnológica, debía ampliar los recursos humanos implicados en la extracción más allá del 
personal del que directamente disponía en plantilla, subcontratando una parte sustancial, si no la totalidad de la producción, a las cuadrillas de destajistas autónomos. El empresario había de velar, al respecto, por un factor que condiciona su competencia: mantener en nómina en la propia firma a los pedreiros de probada destreza en el oficio, mediante promociones en escala y aumento de la paga. Por añadidura, debía acordar con destajistas experimentados un volumen de producción al mes, retribuido por $\mathrm{m}^{3}$ producido, así como qué instrumental aporta cada parte. Llamo la atención sobre la importancia del acordo entre canteiro y destajista: fórmula ritual de carácter esta vez exclusivamente expresivo-protocolario, y a partir de la cual se genera un arreglo potencialmente duradero mientras resulte mutuamente provechoso. Pero una relación que se instituye, ipso facto del acordo, sobre un drástico principio de asimetría. Quedaban asignadas al destajista la plena disponibilidad espacio-temporal y laboral, la responsabilidad -y tensión derivadadel control de los tiempos, intensidad y resultados de la producción; así como la gestión de la seguridad, contratos, retribuciones de los propios empleados y el mantenimiento de un clima de trabajo positivo. Mientras, el cantero-propietario únicamente asumía la remuneración pactada por $\mathrm{m}^{3}$ de piedra, delegando en los destajistas el control técnico directo del proceso extractivo. Un ostentoso rasgo añadido a esta posición categorial descollante del canteiro-propietario era el incomparable arbitrio personal de su tiempo: podía no presentarse al pie de su propia cantera sino al comienzo de la jornada, para dar indicaciones al encargado, o de no hacerlo durante días. Esta figura del canteiropropietario es hija del esquema cultural que estructura y caracteriza asimétricamente la actividad industrial capitalista, informada por un ethos competitivo-mercantilista, y que mediante la delegación de cargas en las cuadrillas destajistas subcontratadas supedita el ethos reciprocitario de éstas a un papel instrumental.

Subordinado dentro de la organización de la gran empresa, el encargado, capataz con dilatada experiencia, tiene por responsabilidad transmitir a los empleados en plantilla de la firma los objetivos de producción diaria o semanal, supervisar el desarrollo del proceso y el ritmo de trabajo. El encargado "controla la piedra que hay que mover. Él se encarga de que se saque lo que dice el propietario que hay que producir, y ahí es donde aprieta él a su gente: los de la propia empresa". El encargado, desde un rol técnico de control, defiende sin ambages los intereses de la empresa; en contraste, en las explotaciones subcontratadas, el destajista se sitúa del lado de su propio equipo de empleados, siendo a la par líder y responsable de su rendimiento. Pero a pesar del 'distanciamiento' estructural del encargado respecto a los pedreiros empleados, contrastado con el paternalismo del destajista con su cuadrilla, también el primero, como el segundo, se torna en instancia a la que apelan solicitantes, amigos o conocidos, de cara a facilitar la incorporación de un trabajador a la cantera. Para ello cuenta con cierta capacidad efectiva, siendo también quien evalúa las cualidades y eficacia de cada operario. Este rasgo de medianero, por el que asimismo puede apoyar discrecionalmente mejoras retributivas ante la dirección, comporta un 
refuerzo del ascendiente personal del encargado. Los intereses interpersonales creados de tal modo introducen elementos que matizan la rigurosa racionalidad mercantil en la organización jerarquizada de la gran empresa de cantería.

De la otra parte, una situación categorial dependiente, sin ser subordinada desde el punto de vista técnico de la actividad, pasó a ocuparla ese destajista, cantero autónomo experto que lidera una pequeña cuadrilla de empleados. Si obtiene un volumen excedentario de producción sobre las cantidades acordadas, el destajista puede sumar ventajosamente ese remanente a lo aportado al propietario, o beneficiarse de venderlo directamente a un taller de piedra y repartir una prima. Si no se alcanza el volumen acordado, corre el riesgo de ver disuelto el acuerdo. El cantero destajista constituye la pieza maestra del nuevo sistema industrial de organización y acumulación del capital en la cantería, pues simultáneamente actúa como intermediario entre los operarios a su cargo y el mercado de trabajo, y como patrón mediador entre los intereses de aquellos y las fuertes exigencias de dedicación, ritmo y esfuerzo precisos para cumplir con las cuotas de producción acordadas. Por la primera faceta mediadora, es quien negocia los destajos y controla el rendimiento de los suyos, actuando como eslabón que, en el proceso de acumulación del capital, encadena la actividad de la pequeña empresa a los intereses de los grandes propietarios. Por la segunda faceta, tiende a incrementar aún más la acumulación, al asumir cargas fiscales, salariales, cuotas sociales y cánones de los que por tanto exime al cantero-propietario receptor de la piedra.

El destajista, aun siendo autónomo, dirige una empresa estructuralmente precaria, integrada por oficiales de segunda, peones y aprendices, continuamente obligada a desarrollar una intensa actividad productiva. Poniendo el instrumental, llevando la electricidad, agua y accesos a pie de cantera, asume además las antedichas retribuciones, licencias y cargas laborales. Ante incertidumbres sobre las oportunidades de trabajo rentable en la zona, a menudo ha de desplazarse por largas temporadas con la cuadrilla a otros territorios (Norte de Portugal, País Vasco, Castilla, o incluso Angola) para aprovechar ofertas de explotación, ampliar el negocio y eventualmente dejar de depender del destajo. Su ideal, a menudo improbable, es "tener una cantera... y no soltarla... Siempre podrás seguir sacando más abajo [explotando el granito, profundizando]”. Pero de no conseguir esa consolidación, la situación precaria de sus empleados se cronifica, al estar contratados por objetivos, directamente dependientes de acordar destajos. Por ello, la relación entre los empleados y el jefe resulta ambigua y a menudo contradictoria: (1) de un lado, el ethos reciprocitario de la cantería tradicional se reproduce en las actuales cuadrillas de destajistas autónomos, dándose una estrecha vinculación -a veces reforzada por parentesco- y compartiendo mano con mano esfuerzos, riesgos, horarios y almorzos en las jornadas de trabajo en la bancada. Performativamente, esto genera confianza en el trato y seguridad de contar con el jefe y los compañeros en situaciones 
de dificultad. Confianza nula en la estratificada relación entre propietario-encargadoempleados en la gran cantera. Tal clima de trabajo y cierta "camaradería paternalista" son fundamentales para retener a los trabajadores experimentados en el equipo: "A un jefe que non se preocupa de que a xente estea contenta no traballo, e anda sempre a apretar... $e$ non escoita cando un ten unhas necesidades, logo márchanlle todos para outros canteiros". (2) De otro lado, el jefe exige rendimiento, pero los empleados experimentados alcanzan un nivel de capacitación que les torna en potenciales autónomos. Cuando no se desligan del destajista para continuar autónomamente, estos trabajadores presionan para mejorar sus retribuciones, y tratan de estabilizar su situación hablando con amistades y contactos personales para integrarse en una gran empresa. En estas condiciones, el jefe destajista suele jugar en desventaja a la hora de retener a sus principales oficiales, dado que las indudables ventajas de ingresar en plantilla en una gran cantera, y contar con un sueldo desahogado, convierte explotaciones como las de Atios y Budiño en meta de las expectativas de promoción en toda la comarca:

"Si sabe poner os tiros e tal, ise ó mellor xa vai para onde pagan mellor. Iso é fijo: xa vai ónde lle fagan un contrato dos bós, e lle pagan ben, porque xa é de outra categoría; e acaban por ire ónde os grandes, porque onde máis pedra se move é onde mellor se paga";

"Buscaba eu o choio... Había amigos alí [en Atios] que estaban traballando, $e$ rendía no choio e... Pois quedaba aí... (...) Cambeaba eu, porque si me pagaban máis, xa escapaba (...) Eso é mediante amigos, todo. Ti vas falando así, tal, “¿Ves un billete máis? ¡Adiós, adiós! 'Ahí te quedas'. Ou as pagas, ou se non...”.

Este flanco débil, difícilmente controlable por el empresario destajista, y que responde, esta vez, a una racionalidad competitiva y mercantil, recuerda la apreciación de Krackhardt y Kilduff al respecto de la influencia, en contextos de mercado, de las redes de relaciones personales:

"Interpersonal networks are one of the media through which organizational culture is maintained and challenged.(...) To the extent that the culture of the organization is transmitted and transmuted by the friendship network, it is clearly outside the control of the formal organizational socialization and reward system." (Krackhardt y Kilduff, 1990:151).

Pero es el singular modo de incorporación de los jóvenes al oficio el aspecto que, conexo al destajo, revela elocuentemente el núcleo estratégico del modo de acumulación del capital actualmente dominante. Entre la década de los '70 y la actualidad, la incorporación de los aprendices a la cantería extractiva sigue respondiendo principalmente a una pauta tradicional, al depender de su implicación en redes de relaciones amicales o parentales, asociadas a mediaciones y al conocimiento personal; tramas en donde 
perdió importancia la vecindad parroquial, cobrándola la propincuidad de municipio o de localidades próximas entre solicitante y empleador. Esto es por lo que se refiere al aprendiz o pinche, y al período en que cobra experiencia como peón, en cuadrillas de pequeñas dimensiones. Padre, hermano, un tío o un amigo "fala" (nótese el carácter ritual de este acto de habla) con el jefe de un destajo, que puede ser un pariente, cuñado, vecino o conocido de la localidad; y le solicita incorporarle en prueba: "Y claro, luego el rapaz también tiene que responder, tiene que valer, porque también es un compromiso para el padre". El objetivo es "coller oficio". Lo destacable es que quienes se incorporan son adolescentes que, a diferencia de otros oficios industriales o de servicios, no han dispuesto para su adiestramiento práctico en la cantería de cauces formativos reglados, sino que se han sometido a la vinculación directa y personalizada con algún canteiro; lo que implica que la formación se identifica con la actividad y exigencia productiva ya desde el primer día:

"Si; D.... e T... dan traballo; son os canteiros de aquí (...) si é por ser veciños, non... E porque xa existe una relación, una confianza... Xa nos conocemos todos aquí, e se sabe cómo funciona cada un ¿non?... E si son de aquí os que colle, é porque hai un conocimento máis grande... e eres de aquí, da mesma parroquia. Pero non é por ser [de la misma parroquia, la causa de la selección] porque o outro é de alí, de Parderrubias, e tamén da traballo aquí, a guichos de Entienza (...) o que é, é que un valga para o traballo. O que non move pedra, xa vai pa afora; se chegas tarde e tal todolos días, nada; xa podes ser de onde sexas, que non hai nada que facer".

Este modo de iniciación -y continuidad- tradicional marca la pauta de incorporación al oficio, aunque no siempre, debido a la escisión de la actividad en dos especialidades a lo largo de las últimas décadas, con el auge de los aserraderos de elaboración de piedra. Hoy en día, numerosos jóvenes se inician en el sector en tales talleres. Sin embargo, esos aprendices pronto intentan trasladarse a la cantería extractiva, dado que sus retribuciones son superiores a las de los aserraderos, procurando ingresar en una cantera tras haber desarrollado cierta experiencia y crédito personales en el taller. De nuevo es preciso el recurso a contactos personales.

Además, avanzando en la vida profesional, ulteriores adiestramientos en el empleo de tecnologías sofisticadas, requeridas por la actual extracción intensiva y a gran escala, tampoco se desarrollaban mediante cursos reglados, exceptuados manejo de vehículos pesados o de explosivos. Puede ser que la empresa suministradora de una tecnología puntera adiestre en su utilización a operarios de la explotación; pero lo habitual es que la nueva tecnología se encomiende inicialmente a autónomos especialistas - por ejemploen corte con hilo diamantado y, por observación, los pedreiros se familiaricen en la práctica con el manejo del instrumento.

La falta de una formación reglada del cantero se aúna a una pronunciada tendencia al abandono escolar temprano, particularmente patente en la comarca y clave para 
interpretar el fundamento estratégico del modo de acumulación del capital vigente hoy en día en la cantería comarcal. Así, según un actual responsable municipal de empleo,

"Pero es que aquí hay un problema: el colegio. Tira más el empleo inmediato que el colegio. Sí. Antiguamente era porque había un exceso de trabajo y se ganaba mucho dinero: aquí cualquier chaval que fuera a trabajar a la cantera ganaba 2000-3000€ al mes con suma facilidad... Entonces, el que se quedaba estudiando era el tonto... $Y$ ahora mismo es una cuestión de que no dan quitado los estudios, no me preguntes por qué... Y ahí chocamos."

En suma, dos factores aseguran una continua reposición generacional de mano de obra disciplinada en un sistema productivo que, así, garantiza una elevada acumulación de capital para las principales empresas, combinándose estratégicamente con la extensión de la producción al destajo:

1) Una formación, y capacitación ulterior, en la cantería extractiva, recurriendo a la pauta pragmática tradicional de aprender directamente trabajando; lo que habitúa desde el primer momento al aprendiz -y después al peón- a una actividad físicamente extenuante, intensiva, arriesgada y relativamente precaria. Esto es garantizado por su incorporación a las pequeñas cuadrillas de destajistas que siguen cultivando un ethos reciprocitario, mediante la vieja ritualidad de trato, cooperación y distribución compartida de horarios y espacios. Una formación de acceso personalizado, no encorsetado por requisitos de acreditaciones curriculares, y que descarga toda la responsabilidad acerca del principiante, no sobre las grandes empresas, sino sobre las pequeñas subcontratadas localmente arraigadas. Esta estrategia de delegar formación y gastos sociales se concierta con; 2) una retribución superior a la que puedan aspirar muchos de los jóvenes que se dediquen en la zona a otro oficio, a costa de limitar drásticamente las expectativas personales de formación general y profesional. Bien es cierto que las mayores retribuciones y mayor estabilidad se obtienen ingresando en las plantillas de las principales canteras porriñesas y salcedenses, lo que hace de acceder a ellas ambición común; pero las limitadas posibilidades de acceso están restringidas a quienes ya hayan desarrollado una gran experiencia en el oficio a través de su desempeño como destajistas: “(...) luego, cuando es una cantera ya grande (...) se contrata al que vale, porque ya lleva años trabajando en canteras. (...) lo que se mira es únicamente que valga para mover piedra, y es lo único..."

El caso es que, en correspondencia con esta reorganización industrial-destajista, mecanización y aumento retributivo, el perfil simbólico del oficio de cantero se invierte a finales del s. XX respecto a su negativa y modesta caracterización tradicional, aunque su nueva imagen aúne ambiguamente los aspectos positivos de la competencia y prosperidad, al estigma de la rudeza de condiciones de trabajo. Así, según un canteiro de unos cuarenta años, que rememora su viejo oficio doce años después de convertirse en chofer de camión: "Na canteira tiña unha vida moi boa. Traballaba en Atios. Iso nada... 
que iso era unha festa todo. ¡Era unha festa!”.

Y sin embargo, contradictoriamente, cuando se le pregunta más adelante qué le motivó para el cambio de oficio: "Porque a canteira é unha cabrona de la hostia. Pero bueno... Porque é duro. Había que estar á chuvia... e frío... Enton, claro; houbo que buscarlle unha solución."

\section{LA CRISIS DE 2007-2013: PRECARIZACIÓN, DIVERSIFICACIÓN OCUPACIONAL Y RESISTENCIA DE LA CANTERÍA. LOS NUEVOS REFERENTES NO LABORALES DE VINCULACIÓN VECINAL}

Tal como ilustra, páginas arriba, el gráfico de distribución porcentual de la población ocupada según rama de actividad entre 1981-2011 en Salceda de Caselas, las cifras de la industria y de la construcción declinan abruptamente después del auge de principios del siglo XXI, descendiendo respectivamente de un $40.6 \%$ a un $31.7 \%$, y de un $16 \%$ a un $11.2 \%$. El llamativo ascenso de los ocupados en servicios de un 39.5\% en 2001, a un $55 \%$ en 2011, revela que, aunque también este sector se resintió de la crisis, mantuvo su pujanza inigualada ya desde los años ochenta. Una tendencia positiva que le lleva a superar a industria y construcción, y que sólo resulta equiparable al desplome definitivo del sector agropecuario:

Fig. 2a. Afiliaciones en alta de la seguridad social durante los años de la crisis. Salceda de Caselas

\begin{tabular}{|l|l|l|l|l|l|}
\hline Año (dic.) & Total & Agricultura & Industria & Construcción & Servicios \\
\hline 2009 & 3359 & 88 & 1067 & 430 & 1774 \\
\hline 2010 & 3408 & 78 & 1051 & 452 & 1827 \\
\hline 2011 & 3316 & 84 & 1005 & 402 & 1825 \\
\hline 2012 & 3105 & 69 & 969 & 319 & 1748 \\
\hline 2013 & 3092 & 47 & 926 & 324 & 1795 \\
\hline 2014 & 3166 & 41 & 946 & 322 & 1857 \\
\hline 2015 & 3301 & 42 & 966 & 316 & 1977 \\
\hline
\end{tabular}

Fuente: Instituto Galego de Estadistica http://www.ige.eu

La diversificación de las bases de actividad, asociada a la urbanización y al dinamismo de los servicios, hace que este sector ya represente un 60\% del empleo en Salceda de Caselas en diciembre de 2015, habiendo triplicado su peso desde inicios de la década de los ochenta. Además, un examen de las ofertas de empleo en 2014-16 descubre la extrema 
heterogeneidad tipológica de los servicios, que abarcan desde peones de limpieza hasta auxiliares administrativos; desde mecánicos hasta electricistas; instaladores, docentes, servicio doméstico, comerciales, cajeros, reponedores, auxiliares de programación, etc. Comercio, hostelería y transporte representan los tres referentes del sector. Por detrás queda la oferta "en abierto" de empleo industrial y de la construcción: desde fresadores, soldadores y carretilleros hasta especialistas en mecanizados o en oxi-corte; desde fileteadores de pescado hasta ingenieros de soldadura; desde peones de albañil hasta encargados de obra, arquitectos técnicos.

Es muy significativo señalar que si la oferta de empleo, para el conjunto de actividades, procede hoy en día, además de la propia Salceda, principalmente de los contiguos Porriño, Mos y Tui, dado el gran dinamismo de los polígonos allí instalados, también lo hace de localidades de otras comarcas, incluidas Salvatierra y Ponteareas, al Este, o Tomiño, y Oia, al Oeste. Sin embargo, la población salcedense ha polarizado sus demandas de empleo a escala comarcal, de un modo marcado y casi exclusivo, en Porriño y Mos, poniendo de manifiesto una "territorialización cultural de la esfera laboral" que, interpreto, constituye una actualización de la cultura tradicional del empleo, tal como venía planteándose a lo largo del último medio siglo. Una actualización no exenta de impulso inercial. Así, según un técnico de empleo municipal:

"A ver: la gente por aquí,... sólo mira para un lado. Es decir, en Salceda tenemos alrededor Ponteareas, A Cañiza, Arbo, Covelo... La gente mira para Porriño y Vigo... no mira aquí hacia Salvatierra y... Mira que hay empresas... ¡Nadie va, o casi nadie va hacia allí a buscar trabajo! Puenteareas es una ciudad que genera muchos puestos de trabajo... Arbo tiene un polígono que genera puestos de trabajo. Si no se dan cuenta que... donde a una empresa de Porriño le llegan cien currículums para una oferta, a Arbo llegan cinco... Es decir; la probabilidad de encontrar trabajo es más alta... Y llegar a Arbo desde aquí [Salceda] son 20 minutos (...) Es decir, que no está lejos. Pero tenemos una barrera psicológica de cargo... Es como la gente de Vigo: 'Salceda, ¡Hostia, Salceda está... muy lejos'! Y la gente de aquí es 'Arbo... ¡Arbo está muy lejos!"

Para dar cuenta de tal tendencia, hay que considerar que Porriño, Salceda y Mos se han ido aquilatando durante décadas como centros gravitatorios y símbolos de riqueza y empleo sobre la base de sus canteras y la automoción. Ya apunté al principio que existen sectores específicos de actividad, con distintivas culturas del trabajo, y empresas y enclaves vinculados, que alcanzan a ejercer históricamente una influencia nuclear en la vida local, organizando y condicionando las expectativas de empleo. Esta fijación axiológico-cultural explica asimismo que el sector de automoción siga constituyendo un atractivo referente laboral para el trabajador salcedense: 
"Lo de auxiliar de automoción... ahí sigue habiendo muchísimo empleo. Es más: creció. De gente de Salceda que se mueve para allá, para Porriño, o para acá: tenemos auxiliares en Salvatierra; tenemos auxiliares en Monzón, que aunque es Portugal está a cinco minutos. Entonces, auxiliar de automoción sí que sigue generando muchos puestos de trabajo... Es más: es uno de los sectores que contribuyó a la incorporación de la mujer al mercado de trabajo."

La última precisión apunta a una singular tendencia innovadora dentro de este nicho industrial, ya tradicional, que sintomáticamente no ha seguido en absoluto el empleo en la cantera o la construcción: la feminización de la ocupación. En el período inmediatamente anterior a la crisis de 2007, la coyuntura económica positiva era tal que el desempleo descendió al mínimo en la localidad, quedando sin cubrirse parte de las ofertas en automoción -debido en mucho al empuje de construcción y canteras-. En ese momento, comenzaron a acceder mujeres como auxiliares, sin que esta tendencia obedeciese a políticas de cuotas, sino por estricta necesidad industrial de trabajo especializado. Como resultado, la desproporción entre trabajo masculino y femenino, pasó de un 75\% / 25\% a un actual 60\% / 40\%. El informante señala una valoración que localmente se hacía al respecto:

"Una bestialidad, el trabajo que había por aquí.. Había quien quería mujeres por una cuestión de maña... en el tema de cablerías y demás... Pero es que en muchos casos no había alternativa. Aquí, el paro que había de hombres... era de hombres que no querían trabajar, por cualquier circunstancia... que estaban apuntados en la oficina de empleo... por lo que fuera, pero que no querían trabajar."

Para interpretar por qué esto sucede en la automoción y no en la cantera, puede sernos de parcial utilidad una sugerencia teórica de Griffith:

(...) some analysts have shown how industries rely on sexual, ethnic, and national distinctions among workers to undermine the political power and class consciousness of labor (...) thus reinforcing myths about certain groups of people being biologically or culturally predisposed to assume specific positions in the (...) division of labor. (Griffith 1987:839).

Dejando al margen la evolución positiva de la constelación de los servicios y del empleo en automoción, paso a la otra cara de la moneda: la construcción. Este sector, en contraste, retrocede continuamente en el panorama local del empleo, hasta el punto de haber perdido un 27\% de sus efectivos en el período 2009-2015; aunque la particular incidencia del trabajo sumergido en la albañilería dificulta la estimación de las cifras reales de ocupados efectivos. Este trabajo sumergido permite entrever, en parte, la razón de la significativa presencia de desempleados inscritos, pero "que no querían trabajar". Además, una particularidad de las empresas constructoras locales contribuyó a agravar 
los efectos de la debacle de la 'burbuja inmobiliaria' sobre la crisis del empleo: los autónomos destajistas de cantería que pretendieron compaginar la obra y promoción inmobiliaria con la extracción de piedra, y que en los tiempos propicios impulsaron el empleo de pequeñas cuadrillas, fueron quienes experimentaron todo el rigor de la depresión hasta desaparecer. También sufrieron el embate los autónomos de la albañilería que habían dado ese salto a la promoción y construcción. Sin embargo, se mantuvieron los constructores tradicionales:

"El que era constructor, que se quedó como constructor con su pequeña empresa de construcción yo creo que... los que yo conozco, siguen ahí... Pero cuando vino la crisis de la construcción, el que diera antes el paso a 'Yo voy a ser promotor, yo voy a hacer obra allí y tal...'ese, cayó."

La perspectiva local de los peones y albañiles puede ensayar modos emic de interpretación de la crisis de la construcción que, sin desconocerlos, parecen obviar los factores globales o regionales que la desencadenaron, para resaltar elementos concretos que pudieron precipitarla según su directa experiencia vital. Se trata de narrativas que arraigan en sus particulares culturas gremiales del trabajo, y se han venido consolidando a través de sus específicas representaciones y ritualidades laborales, basadas -análogamente a los grupos de canteros- en la pericia tradicional de la cuadrilla y en un ethos igualitario que recela de desequilibrios jerárquicos en el oficio. Al respecto, un albañil autónomo, de larga experiencia, señala por qué, a su juicio, se hundieron la empresa en la que trabajaba y, más allá, el sector de la construcción en general:

"O jefe é o que organiza o traballo... Na segunda empresa [en la que trabajó] xa había arquitectos, aparejadores... Aí xa había un montón de xente... ¡había máis xente a planear e a mandar que a traballar!, pero bueno... iAsí afundiu!"

Respecto a estas narrativas de los obreros resulta ilustrativa la interpretación de Dunk acerca de la experiencia que de su crisis de empleo forjaron los operarios canadienses de la molienda de papel que estudió:

"...the experience of these mill workers is a complex phenomenon. An apparent lack of concern about the global situation was not born of an ignorance of it, so much as a sense that either history showed it did not matter or that because one could not do anything about these issues, there was no point in worrying about them." (Dunk, 2002:892).

Por su parte, el empleo industrial, principalmente ligado a las canteras y talleres de piedra, aun castigado, logra mantenerse y repuntar en los dos últimos años, tras haber perdido un $17 \%$ de sus efectivos entre 2009 y 2013. Por el camino quedó un buen número de empleos canteros, en parte arrastrados por el hundimiento de la demanda de obra, debido al citado vínculo con el sector de la construcción. Pero la resistencia de la cantería y el 
mantenimiento de muchas de sus empresas se deben a las fuertes inversiones realizadas de cara a la transformación tecnológica, y al concurso en el mercado global de productos elaborados y diversificados, sobrepasando la mera cantería extractiva. Así, buena parte de las empresas sortearon la crisis:

"Yo creo que las canteras se salvaron un poco más, curiosamente, que la construcción... Bueno: se perdió mucho empleo en las canteras, pero la verdad es que hay muchas empresas que se mantienen, y algunas incluso siguieron invirtiendo. Hubo un cambio en la forma de vender... Hubo que espabilar... El mercado nacional se quedaba pequeño, y hubo que empezar a apuntar hacia afuera... buscar comerciales, técnicos en comercio exterior, y me consta que muchas empresas es lo que están haciendo para recuperar las ventas. $Y$ hay que decir que muchas ya están acomodadas de nuevo a un nivel de ventas interesante... Pero apuntando mucho hacia afuera; tanto a Europa como a América..."

Aunado al aumento de inversiones, internacionalización del negocio y apuesta por la oferta de elaborados de piedra, si no con mayor vigor causal que estos factores, el eje estructural y cultural que, a mi juicio, explica la solidez y continuidad de la cantería en la comarca consiste en la perseverancia de las empresas en el cultivo de la estrategia anteriormente analizada de combinar (1) el encargo al destajo de buena parte de la producción extractiva a pequeñas cuadrillas autónomas cuyos jefes cargan con los gastos salariales y sociales de sus empleados, con (2) la ausencia de formación profesional reglada y continua, descartada en favor de la mera experiencia del ejercicio laboral, de unos operarios cuya promoción depende del crédito que se han ido labrando localmente, y de los contactos personales dentro del ámbito comarcal del oficio -y por tanto, de un control gremial difuso que se hace de sus trayectos profesionales a nivel local-. Y considero que sobre este eje estratégico pivotan la acumulación del capital y la competitividad en la produccióncomercialización a gran escala de las grandes empresas de cantería, pues estas dependen de subcontratar la actividad de esos grupos autónomos de canteros organizados sobre formas morales de vinculación humana, rutinas, ritualidades arraigados en la tradición local, y sobre el veterano ethos del oficio, a la vez reciprocitario y paternalista. El operario semi-precario que actúa al destajo no depende de la postfordista auto-responsabilización individual en una formación profesional reglada, ni en un continuo y obligatorio reciclaje mediante cursillos, como ocurre hoy en los oficios y profesiones de la industria y los servicios. Depende, en cambio, de sus redes personales locales; de su inserción en una cuadrilla en la que, a pesar de todo, es común que alcance cierta turbulenta estabilidad en el empleo; del "mover pedra" contribuyendo a cubrir las cuotas del destajo; de la sólida expertise que como especialista va incorporando, y del incentivo de unos salarios comparativamente altos en el panorama comarcal. Es en esta articulación estructural donde, a pesar de la radical transformación tecnológica, la tradicional matriz cultural 
de organización del trabajo y de formación del cantero se ha preservado y actualizado, subordinada instrumentalmente a la vigente estrategia de acumulación del capital de grandes empresas que concurren dentro de una competencia globalizada.

Pero tal estrategia pasa por que el cantero y su formación se mantengan fuera de los cauces intervencionistas y sistemáticos de formación-control, basados en la estrategia del reciclaje continuado, tutelado por la administración o por las propias empresas, que afectan hoy al resto de oficios industriales y de servicios - patente en la mecánica e industria del automóvil, en la programación informática, en la educación, etc.-. Y dada la potente influencia de la cantería, como cultura del trabajo que proyecta su influjo configurativo al conjunto de la vida social modelando expectativas de vida, no son de extrañar las consecuencias de esta estrategia de acumulación en la juventud salcedense que, cuando pretende acceder a los beneficios de planes de fomento del empleo -en otras ocupaciones-, se ve a menudo atrapada en una inercia negativa, al observar que no alcanza niveles estándares de cualificación profesional, y ni tan siquiera de formación básica general. Según el técnico municipal:

"No. Es gente que viene sin formación ninguna. Pero ninguna, ninguna; además de no tener... O sea, aquí, no tienen ni la formación básica. Es decir (...) gente que no tenía ni la EGB finalizada... una barbaridad. A día de hoy, la ESO... una locura, de hecho aquí preparamos a la gente para la prueba libre de la ESO, porque es un problema serio. Porque hoy en día, para hacer cualquier curso de la Xunta, de acceder y demás, te exigen tener la ESO. Y, entonces, ahí teníamos un límite muy grande, y estamos trabajando en eso ya desde hace tres o cuatro años. Pero vamos, la evolución de las canteras fue un poco así..."

No es un fenómeno que afecte únicamente a la juventud:

"Sí, [en la cantería] incrementó el empleo... Lo que no fue parejo fue la formación, si quieres. Porque cuando vino la crisis, lo que nos damos cuenta al tratar con los trabajadores, es que sí: trabajaron mucho, pero no les dieron formación de ningún tipo, ni técnica ni profesional, para poder tener más autonomía a la hora de elaborar el producto..."

¿Pero cómo es posible explicar esta sujeción -y mantenimiento- de la cantería actual a patrones mixtos destajistas-tradicionales de organización y formación, de modo distintivo a los restantes oficios en los que se ha diversificado el empleo comarcal?

Un aspecto central de la estrategia del postfordismo es la combinación de la reducción de varias formas de protección de los derechos socio-laborales de los trabajadores, con el inculcar la premisa de que la solución real a problemas como el desempleo, la continuidad en el empleo, la promoción o los bajos salarios estriba en el mayor y más continuo reciclaje formativo. El gran cambio respecto a la pasada era fordista-keynesiana consiste en que 
si entonces se insistía en la legislación proteccionista de los derechos del trabajo y las políticas de intervención social como recursos frente al problema de la escasez de trabajo suficientemente retribuido, el pensamiento postfordista proclama, induce y naturaliza la responsabilización individual de los trabajadores en el ajuste a las procelosas realidades del mercado de trabajo -la 'incertidumbre'- mediante un continuo reciclaje formativo. Es decir: el discurso dominante ya no hace recaer la carga del desempleo y la precariedad sobre el sistema, sino que presenta la falta de oportunidades o las penurias económicas como efectos de problemas individuales tales como la personalidad del solicitante o sus deficiencias formativas en "habilidades" que permitan flexibilidad funcional. La solución, por tanto, será el reciclaje y la formación continuada personales: la autotransformación del trabajador. Pero también conlleva la infravaloración de su expertise, de su pericia tradicional incorporada, que pasa a ser considerada como intrínsecamente obsolescente. Y así la pelota se hará rodar en círculos sobre el tejado de un trabajador estructuralmente emplazado en un modo de vida precario e incierto. Dentro de esta lógica, la preocupación de gobiernos y empleadores se focaliza en controlar la cultura de la fuerza de trabajo, disimulada bajo el apodo de "habilidades" o "destrezas", escamoteando, en este discurso, que se perciba la construcción culturalmente relativa de este último concepto. Conforme a esta estrategia, la preocupación explícita por el desarrollo curricular continuo de las "habilidades" del trabajador, actúa en mucho como una cortina que vela el real interés por el ajuste de sus actitudes y la inscripción de la disciplina de mercado en su mente y su ethos (Dunk, 2002:883).

Sin embargo, en el entorno comarcal investigado, este proceso se evidencia en otros empleos industriales y, marcadamente, en los servicios: no así en la cantería. En parte, esto responde a que en la transición de una economía industrial a una de servicios, el trabajo en esta última, por su misma naturaleza, frecuentemente impide que los trabajadores dispongan en sus entornos laborales de suficiente espacio social para desarrollar un conjunto distintivo de valores y actitudes culturales: situación opuesta al caso de la cantera o la obra. Además, la ampliación de la diversidad y libertad de mercado es paralela, en esa circunstancia, al incremento de la vigilancia e intrusión en las vidas de los trabajadores; un control que a menudo se camufla bajo la apariencia de la 'obligada conveniencia' -ciertamente incorporada, asumida- de someterse a formación continuada, cursillos, etc. Y además, la promoción laboral, el acceso al empleo, o las coberturas por desempleo se hacen depender de la participación personal en esos programas. Pero en el caso de la cantería y la construcción concurren distintos factores que las convierten en sectores indóciles a este estilo de individualización por reciclaje permanente. Y dado que sus culturas laborales han informado durante largo tiempo las expectativas y el ethos de la población en torno al trabajo, incluso tras resultar subsumidas en la estrategia de la industria extractiva a gran escala, tales factores han estimulado el sinsentido de la formación reglada para jóvenes y trabajadores con experiencia. 
En primer lugar, como ocurre en el caso de la minería (Burawoy, 1979:242), las restricciones del movimiento de capital y de la oferta laboral que éste pueda atraer, así como la incertidumbre sobre las condiciones de producción en la cantería, derivadas de los riesgos para la seguridad física, y de las limitaciones del medio físico, hacen probable que los trabajadores sean capaces de resistir la expropiación de su pericia tradicional -y el sometimiento a reciclajes periódicos-: entonces, son inefectivos los intentos de introducir una autoridad directiva centralizada y eliminar autónomos y destajos. En parte, esto es debido a que canteras y construcción se encuentran forzosamente radicadas en un determinado territorio, lo que minimiza las posibilidades de deslocalización de la actividad.

En segundo lugar, la transmisión de la información sobre oportunidades de empleo en la cantería y en la construcción continúa circulando a través de redes de relaciones personales. Es decir, a diferencia de lo que ocurre con las ofertas en otros diversos sectores, no menudea la información de oportunidades encauzada a través de servicios de empleo, prensa, anuncios en la red o ETTs. Al efecto, importa exclusivamente el grado de experiencia del candidato en el trabajo en la cantera y las eventuales acreditaciones personales que proporcionen de palabra compañeros, encargados o parientes, además del conocimiento del momento oportuno para solicitar la mediación, o para cursar la solicitud si una explotación pretende ampliar plantilla. El prestigio laboral, las garantías personal y confidencialmente transmitidas, en suma. Pero no ha existido la preocupación de desarrollar documentados currículos profesionales, ni de someterse a entrevistas de trabajo estandarizadas. Puede decirse, en suma, que el predominio económico, influencia cultural y crecida popularidad del trabajo de cantero en las últimas décadas han moldeado negativamente la actitud general hacia la formación profesional, su actualización sistemática y los protocolos formalmente 'normalizados' de gestión de la empleabilidad y recursos humanos.

En tercer lugar, el factor axial estriba en el poder de la propia estrategia de acumulación ya analizada, erigida sobre dos pilares conjugados: dicho descarte de la formación reglada en favor de la experiencia laboral efectiva, de un lado, y el recurso sistemático al destajo de otro. Dentro de este sistema, la formación y desarrollo básico de la pericia en el oficio quedan endosados, por la misma lógica del destajo, a la pequeña cuadrilla encabezada por un destajista autónomo; y es ahí donde, aparte de ser relegada y 'enajenada' la carga de sus riesgos y seguros, el aprendiz y el peón van incorporando un primordial concepto, tradicionalmente grupal y reciprocitario, del proceso y relación productivos característicos del ethos cantero. Es cierto que la experiencia y la misma dinámica jerarquizada de la organización actual del sector inducen valores mercantilistas contrarios, como la progresiva autonomización del trabajador, la normalización de la negociación 
y la búsqueda del incremento retributivo individual como principio supremo a la hora de definir, en momentos críticos, su pertenencia a una u otra empresa. Pero incluso el desarrollo de este enfoque individualista y competitivo, y estos acordos que marcan la promoción, se plantean dentro del entorno comarcal del oficio; y verificados, no a través de cauces estandarizados de empleo, sino a través de esa red personal que, en el caso de Salceda, se extiende en un contorno tradicional que abarca principalmente el propio municipio, y los inmediatos Porriño, Mos y Tui como ámbitos de referencia.

Como vimos, ese contorno donde se cultiva la red de relaciones personales con implicaciones laborales también comprende, aunque mucho más desdibujadamente, territorios situados más al Este. Pues bien, interpreto que la centralidad y poder referencial de la sociabilidad laboral del valle del Louro y del propio municipio salcedense contrastados con la debilidad al respecto de esos otros lugares, constituyen un efecto de la vigorosa influencia simbólico-ritual que la cultura cantera sigue ejerciendo hoy en día sobre las representaciones locales del trabajo, las expectativas de vida, o la formación y la promoción personal.

También es cierto que si el ejercicio de la cantería y la albañilería tradicionales (o preindustriales) mediante sus culturas del trabjo fomentaban una sociabilidad centralizada en cada aldea -en cada parroquia-, debido a que las pequeñas canteras solían explotarse en penedos situados en su territorio o inmediaciones, y a que los canteiros acostumbraban a reunirse, a la tarde, en las tabernas parroquiales, entre sí y con los labregos -de cuya identidad y actividad también participaban-, la cantería actual ha dejado de propiciar este tipo parroquial de sociabilidad, al ampliar y dispersar las redes de relaciones personales al extenso espacio comarcal antedicho. En esto, la cantería industrial ya no actúa como motivo de una ritualidad laboral-esparcitiva que reproduzca el principal referente de la sociabilidad y la vinculación moral tradicionales. En relación a la vecindad parroquial el trabajo, y cualquier 'cultura del trabajo' específica, ha dejado de ser un 'motivo ritual' de convivencia e identificación, pues el ejercicio de una variedad profusa de ocupaciones ejercidas en un ámbito de mayor escala territorial, ha provocado una dispersión vinculativa del vecindario, que despuebla la aldea -salvo de ancianos- durante el día. Sin embargo no por ello se han extinguido los ámbitos y ocasiones en los que cultivar la convivencia y ritualizar la identidad vecinal de parroquia. El relevo lo han tomado hoy en día, de un modo singularmente dinámico y específico de las siete parroquias salcedenses, los centros culturales: locales sociales fundados desde la década de los ochenta en cada vecindario, dotados de cafetería-bar y donde se convoca un repertorio de actividades (música, danza, charlas, conciertos, celebraciones festivas, asambleas asociativas y de comunidades de montes), a donde los convecinos de parroquia concurren con una regularidad diaria que antaño sólo conocieron las dispersas tabernas-tiendas aldeanas. 
Es decir: la experiencia y ritualidad compartida de la vida laboral cantera o labriega -el 'modo laboral de relación' y la 'cultura del trabajo' - ha dejado de ser un marco e impulsor cotidiano de la convivencia vecinal y de cultura de la cohesión parroquial. El testigo lo ha recogido la experiencia y ritualidad compartidas del esparcimiento diario y las reuniones asociativas, adoptando un 'modo esparcitivo-asambleario de relación'.

\section{CONCLUSIONES}

El influjo de una cultura del trabajo hegemónica puede ser decisivo en la conformación de la experiencia vinculativa y las expectativas vitales del conjunto de la población a lo largo de un período histórico más o menos dilatado. Durante las décadas finales del s. XX, el desarrollo de la cantería industrial del granito en las comarcas del sur de Pontevedra, llegó a convertir en dominante la cultura del trabajo de esta actividad, dentro de un panorama socioeconómico en rápida urbanización y diversificación de las bases productivas y de empleo. La transformación de la cantería tradicional en industrial se ha articulado en dos ejes estratégicos. Por un lado, el desarrollo de una estructura de interdependencia asimétrica entre empresas altamente capitalizadas, competidoras en un mercado global, y pequeñas cuadrillas que producen a destajo para aquellas, permitiéndoles intensificar su estrategia de acumulación del capital al eximirles de costes y gestión de trabajo, seguridad y formación; estrategia posibilitada gracias a una condición clave: que las cuadrillas de destajistas mantengan y reproduzcan -aun asumiendo las innovaciones tecnológicas- una cultura organizativa tradicional, basada en una ritualidad laboral inductora de un específico ethos paternalista y reciprocitario. Concomitantemente, el otro eje que consolida la estrategia de la cantería industrial consiste en la pauta tradicional de formación de los aprendices, desarrollada en el curso de la interacción cotidiana en el seno de tales cuadrillas de destajistas, y a través del adiestramiento práctico a pie de obra, en el propio proceso laboral. Esta formación, verificada exclusivamente mediante la inmersión en la praxis laboral directa, y que propicia la alta valoración de la experiencia y la pericia acumuladas durante años en el oficio, torna a los canteros en reacios a las políticas oficiales de formación reglada y continua. A lo largo de las primeras décadas del s. XXI, en la comarca considerada, han ido adquiriendo constantemente un mayor peso económico y laboral una gran diversidad de actividades industriales $\mathrm{y}$, principalmente, de servicios, que han pasado a ofrecer ocupación a buena parte de la juventud local. Sin embargo, tales actividades, en general debido al aislamiento relacional, temporalidad y precariedad ocupacional a los que someten al empleado, no han instaurado culturas del trabajo que desplacen definitivamente el predominio de la cultura del trabajo cantero, ni el prestigio social y prosperidad económica que éste ha generado y simbolizado desde la década de los ochenta del siglo XX. A escala del conjunto de la población, esta influencia de la cantería, su ethos organizativo, simbolismo y estilo formativo, basados en redes locales y comarcales de relaciones personales, ha derivado en un problema: que las reticencias y dificultades de comprensión hacia la práctica de la formación continuada, 
el reciclaje ocupacional, y hacia el aprovechamiento de las oportunidades institucionales de las estrategias de inserción laboral, se hayan extendido a ese amplio sector, en general, de la juventud demandante de empleos en otros sectores; sectores en que sí se encuentra sólidamente implantada la exigencia del cuidado de un perfil profesional individualizado, permanentemente actualizado en las cambiantes habilidades que precisa el mercado.

Pero, de otro lado, una cultura del trabajo hegemónica puede dejar de ejercer su influencia conformadora de algunos aspectos de la vida social, aunque la mantenga en otros. Así, la cultura del trabajo cantero industrial ha perdido el papel de marco de referencia nuclear para la convivencia vecinal de aldea que la cantería manual del pasado y la labranza, dominantes en el Condado y Baixo Miño pontevedreses, ejercieron hasta su desaparición en la década de los ochenta. La dispersión cotidiana de la población activa fuera de la aldea, y en un amplio territorio comarcal, en el ejercicio de sus nuevas y habituales prácticas laborales y de esparcimiento, han provocado que el 'modo laboral de relación' que labranza y cantería imponían en el pasado, haya dejado de ser. En su sustitución, el cultivo de la convivencia vecinal y la expresión celebrativo-ritual de su unidad es hoy verificada centralmente a través de actividades asamblearias y celebrativas desarrolladas en los centros culturales parroquiales. Este proceso me lleva a sugerir que, bajo ciertas condiciones históricamente cambiantes, el 'modo laboral' y la cultura del trabajo pueden combinar su influencia en la definición del ethos y patrones de identificación y relación sociales, con un 'modo esparcitivo-asambleario' y una cultura celebrativa; o incluso ver sustituido su predominio por el de esta última en terrenos o marcos vinculativos donde la ocupación ha dejado de informar unitariamente el horizonte de representaciones y expectativas de relación y proyectos vitales de la población. Todo ello conduce a la necesidad de considerar siempre, a efectos analíticos, cuáles son los límites y condiciones de posibilidad en que una determinada cultura del trabajo actúa efectivamente como modulador de la interacción social y orientador de la específica cosmovisión de un colectivo humano, en el sentido de que probablemente el condicionamiento y los patrones de la "cultura del trabajo", con ser a menudo decisivos y casi siempre presentes, probablemente no sean determinantes u omnímodos en su afectación de todo proceso de la experiencia social. 


\section{BIBLIOGRAFÍA CITADA}

Asad, Talal (1983) "Anthropological conceptions of religion: reflections on Geertz. Man, 18, pp. 237-259.

Bloch, Maurice (1989) Ritual, History and Power: Selected Papers in Anthropology. London: Athlone.

Burawoy, Michael (1979) “The Anthropology of Industrial Work”. Annual Review of Anthropology 8, pp. 231-266.

Couceiro, Enrique (2008) Labrado de gentes. Matrices culturales de las prácticas colectivas en la aldea gallega y su transformación. Pontevedra: Diputación de Pontevedra.

Dunk, Thomas (2002) "Remaking the Working Class: Experience, Class Consciousness, and the Industrial Adjustment Process". American Ethnologist 29, pp. 878-900.

Griffith, David C. (1987) "Nonmarket Labor Processes in an Advanced Capitalist Economy". American Anthropologist 89, pp. 838-852.

Kelly, John, y Kaplan, Martha (1990) "History, Structure, and Ritual". Annual Review of Anthropology 19, pp. 119-150.

Krackhardt y Kilduff (1990) "Friendship Patterns and Culture: The Control of Organizational Diversity”. American Anthropologist, 92, pp. 142-154.

Leach, Edmund (1976) "Ritual". En Enciclopedia Internacional de las Ciencias Sociales, Vol. 9. Madrid: Aguilar. pp, 383-388.

Palenzuela, Pablo (1995) "Las Culturas del trabajo: una aproximación antropológica". Sociología del trabajo 24.

Rappaport, Roy (2001) Ritual y religión en la formación de la humanidad. Madrid: Cambridge University Press.

Trist, Eric., Higgin, G . W., Murray, Hugh y Pollack, A. B. (1963) Organizational

Choice. London: Tavistock. 